\title{
Randomized Intra-patient Controlled Trial of Mepilex Lite Dressings versus Aqueous Cream in Managing Radiation-Induced Skin Reactions Post-mastectomy
} \author{
M Herst ${ }^{5 *}$ \\ ${ }^{1}$ Wellington Blood and Cancer Centre, Wellington Hospital, Wellington, New Zealand \\ ${ }^{2}$ Regional Cancer Treatment Service, Palmerston North Hospital, Palmerston North, New Zealand \\ ${ }^{3}$ Radiation Oncology Department, Southern Blood and Cancer Centre, Dunedin Hospital, P.O. Box 1921, Dunedin, New Zealand \\ ${ }^{4}$ Auckland Radiation Oncology, 98 Mountain Rd, Epsom, Auckland 1023, New Zealand \\ ${ }^{5}$ Department of Radiation Therapy, University of Otago, Wellington, P.O. Box 7343, Wellington, New Zealand
}

Dean B Paterson ${ }^{1}$, Prashika Poonam², Noelle C Bennett ${ }^{3}$, Ruth I Peszynski ${ }^{3}$, Meredith J Van Beekhuizen ${ }^{4}$, Marieke L Jasperse ${ }^{5}$ and Patries

\begin{abstract}
Objective: Severe acute radiation-induced skin reactions occur in a significant proportion of women who receive radiation therapy for breast cancer. We previously showed that Mepilex Lite dressings decreased the severity of erythema. Here we report their effect on the full range of skin reactions in 74 breast cancer patients post-mastectomy.
\end{abstract}

Methods: A total of 80 women were recruited from four hospitals in New Zealand with 74 women contributing a full data set for analysis. The first skin area on the chest wall to develop erythema was randomly divided into two similar halves; one half was treated with Mepilex Lite dressings, the other half with aqueous cream. Skin reactions were assessed using the Radiation-Induced Skin Reaction Assessment Scale.

Results: Compared with aqueous cream, Mepilex Lite dressings did not significantly reduce the incidence of moist desquamation but did reduce the overall severity of skin reactions by $41 \%(p<0.001)$, the average moist desquamation score by $49 \%(p=0.043)$ and the sum of the moist desquamation time for all patches by $28 \%$ from 25 to 18 weeks. Most patients preferred the dressings, found them easy to use and very comfortable to wear.

Conclusions: Mepilex Lite dressings reduce all aspects of radiation-induced skin reactions.

Keywords: Radiation therapy; Breast cancer; Post-mastectomy; Skin reactions; Moist desquamation; Mepilex Lite; Aqueous cream

\section{Introduction}

Radiation-induced skin reactions occur in $80-90 \%$ of breast cancer patients by completion of treatment [1]. To date, there is no standard treatment for radiation-induced skin reactions. In a recent survey, Kumar, et al. [2] found that $50 \%$ of responding departments in Australia and New Zealand based their skin care policy on anecdotal evidence. This situation is not limited to Australasia; skin care practices vary both between and within institutions worldwide [3-5]. A good example of this is the widespread use of aqueous cream in many radiation therapy departments around the world, even though a large randomized controlled clinical trial (RCT) $(n=357)$ showed that aqueous cream does not prevent nor decrease the severity of skin reactions [6].

Bolderston, et al. [7] reviewed the efficacy of a range of products in managing acute radiation-induced skin reactions. The authors found that none of the topical interventions (corticosteroid creams, sucralfate cream, hydrocolloid dressings and a moisture vapour permeable dressing) significantly reduced the severity of skin reactions. Further management trials published since this review have shown a lack of effectiveness for silver-leaf nylon dressings [8] compared with silver sulfadiazine cream in 12 head and neck patients, a non-adherent absorbent dressing in 146 head and neck patients [9], and a hyaluronic acid based cream for the management of erythema in 200 patients with breast cancer [10]. Studies investigating hydrogel dressings for moist desquamation have yielded inconsistent results. An open-label randomized controlled clinical trial $(n=357)$ compared a hydrogel dressing with a dry dressing over a range of treatment sites and found that moist desquamation healed more slowly with the hydrogel $(\mathrm{p}=0.03)$ [11]. In contrast, a much smaller $(\mathrm{n}=33)$ trial reported that moist desquamation was more likely to heal with a hydrogel dressing compared with gentian violet [12].

We recently showed that Mepilex Lite dressings decreased the severity of radiation-induced erythema compared with aqueous cream in 24 breast cancer patients. In addition the dressings were very well tolerated by patients [13]. These results are consistent with previous case studies from Scotland and Stockholm [14]. Mepilex Lite is an absorbent, self-adhesive dressing consisting of a thin flexible sheet of absorbent hydrophilic polyurethane foam bonded to a water vapourpermeable polyurethane film backing layer. The contact surface of the dressing is coated with a soft silicone adhesive layer without any

*Corresponding author: PM Herst, Department of Radiation Therapy, University of Otago, Wellington, P.O. Box 7343, Wellington, New Zealand, Tel: 644 3855475; Fax: 644 3855375; E-mail: patries.herst@otago.ac.nz

Received August 31, 2012; Accepted September 26, 2012; Published September 28, 2012

Citation: Paterson DB, Poonam P, Bennett NC, Peszynski RI, Van Beekhuizen $\mathrm{MJ}$, et al. (2012) Randomized Intra-patient Controlled Trial of Mepilex Lite Dressings versus Aqueous Cream in Managing Radiation-Induced Skin Reactions Post-mastectomy. J Cancer Sci Ther 4: 347-356. doi:10.4172/1948-5956.1000166

Copyright: (c) 2012 Paterson DB, et al. This is an open-access article distributed under the terms of the Creative Commons Attribution License, which permits unrestricted use, distribution, and reproduction in any medium, provided the original author and source are credited. 
Citation: Paterson DB, Poonam P, Bennett NC, Peszynski RI, Van Beekhuizen MJ, et al. (2012) Randomized Intra-patient Controlled Trial of Mepilex Lite Dressings versus Aqueous Cream in Managing Radiation-Induced Skin Reactions Post-mastectomy. J Cancer Sci Ther 4: 347-356. doi:10.4172/1948-5956.1000166

added chemicals. It adheres to healthy skin thus retaining the dressing in position but without causing trauma on removal. The material does not react to chemicals in or on the skin, does not stick to open wounds and can be left on the skin for several days $[14,15]$. As we postulated in our previous trial [13], Mepilex Lite dressings reduce skin reactions by preventing additional mechanical damage (due to friction between damaged skin and clothing or other body parts) and chemical injury (due to perspiration trapped in skin folds to the basal layer) of the skin that has been sub-lethally damaged by radiation. This allows for repair of the fragile skin rather than exacerbating the damage. Other authors have also suggested that providing a protective barrier discourages further injury and promotes healing $[14,16]$.

The current study compares the efficacy of Mepilex Lite dressings with that of a standard aqueous cream in reducing the severity of the full range of acute skin reactions in post-mastectomy patients. Moist desquamation is common in post-mastectomy irradiation and the chest wall provides an excellent model for irradiated skin care practices because of the uniform surface and radiation dosimetry compared to other situations where moist desquamation is common [16].

\section{Methodology}

This randomized, intra-patient controlled, multicentre clinical trial was approved by the Multi-region Health and Disability Ethics Committee in April 2010 and in May 2011 (MEC/10/04/033); and is registered with the Australia New Zealand Clinical Trials Registry
(ACTRN12611000718943). All participants gave written consent before the start of radiation therapy treatment.

\section{Trial Outcomes}

We determined the effect of Mepilex Lite dressings on 1) the overall severity of the skin reactions, 2) the incidence of moist desquamation, 3) the time to moist desquamation, and 4) the time to healing.

\section{Participants}

All women receiving radiation therapy for breast cancer at Dunedin Regional Hospital (DUN), Wellington Regional Hospital (WGN), Palmerston North Regional Hospital (PLN) and Auckland Radiation Oncology (ARO) who had had a mastectomy were screened for recruitment. Recruitment occurred between March 2011 and May 2012. Specific exclusion criteria were: previous radiation therapy to the ipsilateral chest wall, metastatic disease, breast reconstruction, impaired mobility and a Karnofski performance status score of less than 70. Participants also had to be able to return to the department for weekly assessments after the completion of treatment. In total, 80 patients were recruited with 74 women yielding a complete data set for analysis. The flow of patients is shown in the consort diagram in figure 1.

\section{Randomization}

The first erythematous skin area on the chest wall was divided into either inferior and superior halves or medial and lateral halves by the
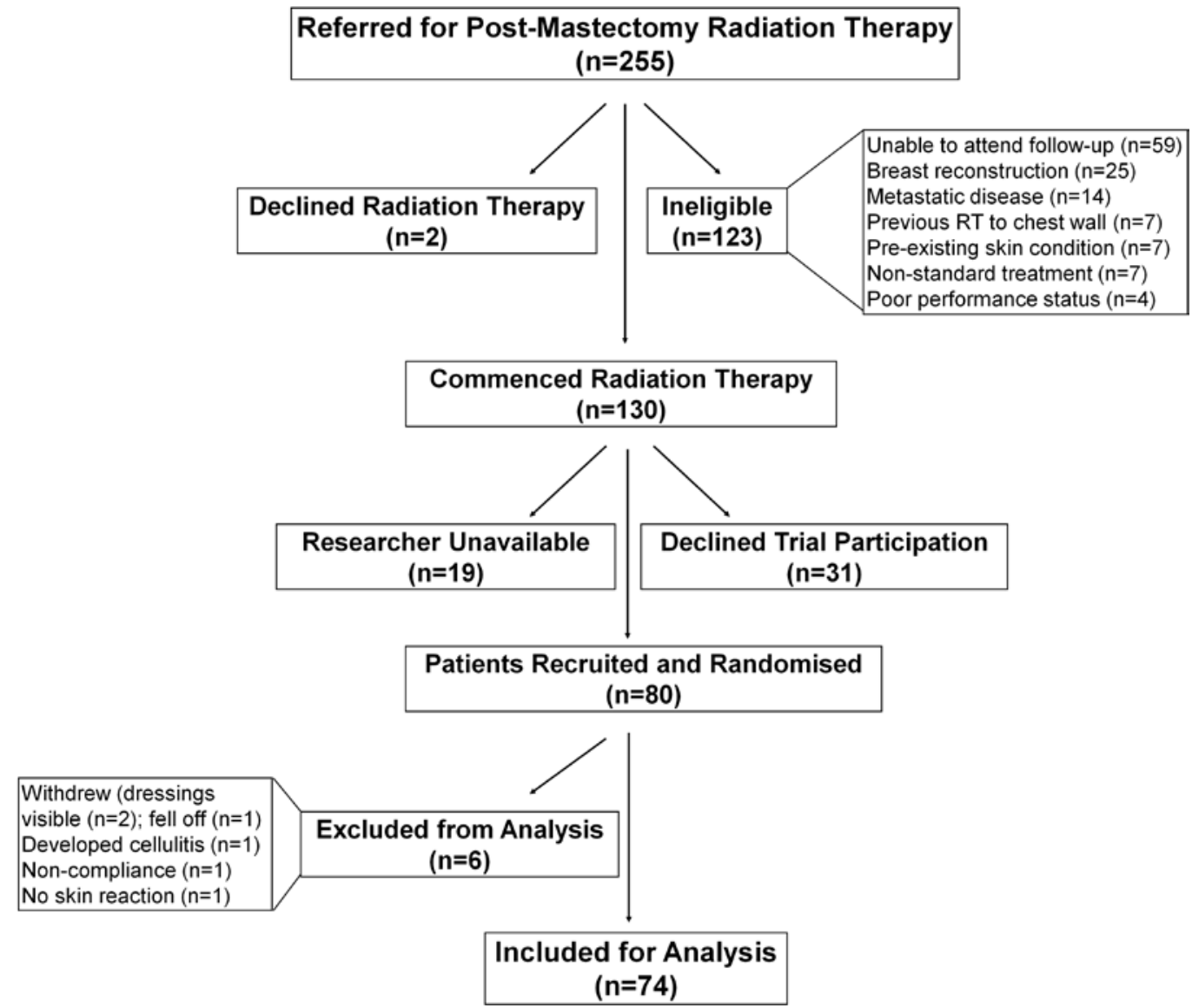

Figure 1: Consort diagram showing flow of patients through the trial. A total of 80 women enrolled in the trial, 74 completed the trial and yielded a full data set for analysis. Most patients who declined to take part in the trial did so because of time commitments. 
Citation: Paterson DB, Poonam P, Bennett NC, Peszynski RI, Van Beekhuizen MJ, et al. (2012) Randomized Intra-patient Controlled Trial of Mepilex Lite Dressings versus Aqueous Cream in Managing Radiation-Induced Skin Reactions Post-mastectomy. J Cancer Sci Ther 4: 347-356. doi:10.4172/1948-5956.1000166

research radiation therapist. Randomization of Mepilex Lite dressings and aqueous control cream was conducted (via randomization fax) by the Principal Investigator (PMH), who had no patient involvement. Randomization was based on pre-prepared computer-generated randomization charts. The dressings were allocated to either superior/ left or inferior/right depending on how the erythematous patch was orientated and had been divided.

\section{Blinding}

Because this trial compared dressings with cream neither the research radiation therapist nor the patients themselves were blinded to the knowledge of which skin area was covered in dressings or treated with cream.

\section{Radiation Therapy Treatment}

Patients were treated in the supine position with their arms supported above their head. All centres delivered radiation therapy to the chest wall using $6 \mathrm{MV}$ or a combination of $6 \mathrm{MV}$ along with either of $10 \mathrm{MV}, 15 \mathrm{MV}$ or $18 \mathrm{MV}$ tangential photon beams. Segment fields were used where required to reduce "hot spots". As an alternative to photon beams, some patients at ARO were treated with a single appositional electron field depending on the treating clinician's preference. The majority of patients had bolus (usually 3 or $5 \mathrm{~mm}$ ) applied to the chest wall daily, however this practice was much less common in DUN. If required, the supraclavicular and axillary lymph nodes were treated with anterior (or near anterior) and posterior photon beams. Table 2 details differences in radiation therapy treatment between the four centres.

\section{Application of Dressings and Aqueous Cream}

Patients doubled as their own controls to eliminate confounding patient and treatment-related factors. Intervention started from the time that the skin first showed erythema, as noticed by the research radiation therapist which was generally about 10-14 days after the first fraction. Only the first erythematous area on the chest wall was included in the trial. Often, other areas on the chest wall showed skin reactions later on in the treatment. Sometimes these later reactions were more severe than those in the area that went red first; however these were not included in the analysis to facilitate statistical analysis.

Mepilex Lite dressings were positioned by the research radiation therapist on half of the area where erythema was present; the other half continued to be treated with aqueous cream (control). Distribution of the dressings was randomized and their localization on the chest wall was indicated by a semi-permanent marker pen, so that patients could accurately reposition the dressings after showering. A tracing of the area was also taken in case the marks washed off and to facilitate dose estimations using the RT planning system. Aqueous cream was applied twice a day to the control patches and other parts of the chest wall that were not part of the study area. Hydrocortisone cream (1\%) was prescribed by some centres to reduce excessive itching when appropriate. The surface area of the skin patches analysed ranged from 50 to $220 \mathrm{~cm}^{2}$.

Mepilex Lite dressings $(15 \times 15 \mathrm{~cm})$ were generously donated by Molnlycke Healthcare LTD; aqueous cream was obtained fromAFT pharmaceuticals (Auckland, NZ) and contained $9 \mathrm{~g}$ emulsifying wax, $10 \mathrm{~g}$ white soft paraffin, $6 \mathrm{~g}$, liquid paraffin, $1 \mathrm{~g}$ phenoxyethanol in boiled and cooled purified water to $100 \mathrm{~g}$.

\section{Moist Desquamation}

Mepilex Lite covered skin patches remained covered in Mepilex Lite if they developed moist desquamation; control patches were covered in

\begin{tabular}{|c|c|c|c|c|c|}
\hline \multicolumn{6}{|c|}{ RISRAS (total scores between 0 and 36 )* } \\
\hline \multicolumn{6}{|c|}{ Researcher Component (total scores between 0 and 24) } \\
\hline $\begin{array}{l}\text { Erythema } \\
\text { (E) }\end{array}$ & $\begin{array}{c}0 \\
\text { Normal skin }\end{array}$ & $\begin{array}{c}1 \\
\text { Dusky pink }\end{array}$ & $\begin{array}{c}2 \\
\text { Dull red }\end{array}$ & $\begin{array}{l}3 \\
\text { Brilliant red }\end{array}$ & $\begin{array}{c}\mathbf{4} \\
\text { Deep red-purple }\end{array}$ \\
\hline Dry Desquamation (DD) & $\begin{array}{c}0 \\
\text { Normal skin }\end{array}$ & $\begin{array}{c}1 \\
(<25 \%)^{* *}\end{array}$ & $\begin{array}{c}2 \\
(25 \%-50 \%)\end{array}$ & $\begin{array}{c}3 \\
(50 \%-75 \%)\end{array}$ & $\begin{array}{c}4 \\
(>75 \%)\end{array}$ \\
\hline $\begin{array}{l}\text { Moist Desquamation } \\
\text { (MD) }\end{array}$ & $\begin{array}{c}0 \\
\text { Normal skin }\end{array}$ & $\begin{array}{c}1.5 \\
(<25 \%)\end{array}$ & $\begin{array}{c}3.0 \\
(25 \%-50 \%)\end{array}$ & $\begin{array}{c}4.5 \\
(50 \%-75 \%)\end{array}$ & $\begin{array}{c}6 \\
(>75 \%)\end{array}$ \\
\hline $\begin{array}{l}\text { Necrosis } \\
\text { (N) }\end{array}$ & $\begin{array}{c}\mathbf{0} \\
\text { Normal skin }\end{array}$ & $\begin{array}{c}2.5 \\
(<25 \%)\end{array}$ & $\begin{array}{c}\mathbf{5 . 0} \\
(25 \%-50 \%)\end{array}$ & $\begin{array}{c}7.5 \\
(50 \%-75 \%)\end{array}$ & $\begin{array}{c}10 \\
(>75 \%)\end{array}$ \\
\hline \multicolumn{6}{|c|}{ Patient Component (total scores between 0 and 12) } \\
\hline \multicolumn{2}{|c|}{ Symptoms } & Not at all & A little & Quite a bit & Very much \\
\hline \multicolumn{2}{|c|}{$\begin{array}{l}\text { Do you have any tenderness, discomfort of pain of your skin in the } \\
\text { treatment area? }\end{array}$} & 0 & 1 & 2 & 3 \\
\hline \multicolumn{2}{|c|}{ Does your skin in the treatment area itch? } & 0 & 1 & 2 & 3 \\
\hline \multicolumn{2}{|c|}{ Do you have a burning sensation of your skin in the treatment area? } & 0 & 1 & 2 & 3 \\
\hline \multicolumn{2}{|c|}{$\begin{array}{l}\text { To what extent has your skin reactions and your symptoms affected your } \\
\text { day to day activities? }\end{array}$} & 0 & 1 & 2 & 3 \\
\hline
\end{tabular}

* Individual scores for each item are added up to give a total score for the researcher and patient components of the scale. Adding the researcher and patient component scores together gives the total combined RISRAS score.

** Percentage of surface area of affected skin.

Table 1: Radiation-Induced Skin Assessment Scale (RISRAS). 
Citation: Paterson DB, Poonam P, Bennett NC, Peszynski RI, Van Beekhuizen MJ, et al. (2012) Randomized Intra-patient Controlled Trial of Mepilex Lite Dressings versus Aqueous Cream in Managing Radiation-Induced Skin Reactions Post-mastectomy. J Cancer Sci Ther 4: 347-356. doi:10.4172/1948-5956.1000166

dressings that were standard for each centre. In DUN and ARO this was Mepilex Lite, in WGN this was hydrogel (SoloSite Gel; Smith and Nephew Healthcare, Auckland), covered with a non-adherent wound contact layer (Cuticerin, Smith and Nephew Healthcare, Auckland) and an absorbent pad (Non-Woven Combine, Smith and Nephew Healthcare, Auckland). In PLN this was standard cotton gauze with Silvadene Cream 1\% (silver sulfadiazine cream from Smith and Nephew Healthcare, Auckland) to prevent wound sepsis.

\section{Measurements}

\section{Severity of skin reactions}

We measured skin reactions using the Radiation-Induced Skin Reaction Assessment Scale (RISRAS) developed by Noble-Adams $[18,19]$ and modified by MacBride, et al. [14]. We used the RISRAS in our pilot study [13] and found that it accurately differentiated between small differences in skin reactions. This scale consists of a researcher component and a patient component. The research radiation therapist scores the visible extent of the skin reactions (with separate scores for erythema, dry desquamation, moist desquamation and necrosis). The patient scores the level of pain, itchiness, burning and effect on day to day life. The researcher and patient scores are then summed to give the combined RISRAS score (Table 1). In order to minimise inter-scorer variability, all the research radiation therapists responsible for the RISRAS scores in their centre as well as their backup scorers (two per centre) attended a one day pre-trial workshop to maximize consistency in RISRAS scoring. During the workshop scorers familiarised themselves with the scoring system using 30 photographs that represented the full scale of skin reactions to be expected on the chest wall of the trial patients. The workshop was facilitated by KV Diggelmann who was the RISRAS scorer in our previous skin trial [13].

\section{Timing of RISRAS measurements}

RISRAS scores were determined three times a week (on Mondays, Wednesdays and Fridays) from the moment erythema was visible until completion of radiation treatment. Weekly assessments were done after completion of treatment until all acute skin reactions had cleared up (usually four to five weeks after completion of treatment). All RISRAS scores for each area were added up and divided by the number of assessments, yielding an average RISRAS score for that area.

\section{Time to moist desquamation}

The date of onset and location of moist desquamation (Mepilex Lite patch, aqueous cream patch or on the skin outside the study area) were recorded for each patient. Moist desquamation was also recorded as part of the RISRAS assessment. At the completion of radiation treatment, patients who had not experienced moist desquamation, were educated on how to recognise it and were instructed to contact the research radiation therapist and return for assessment if moist desquamation developed between scheduled assessments.

\section{Time to healing}

This was defined as the time it took for complete re-epithelisation with new pink skin covering the entire wound area.

\section{Dose measurements}

Due to resource constraints we were only able to directly determine the actual dose received by the skin underneath the Mepilex Lite dressings and aqueous cream patches in 38 of the 74 patients. Thermoluminescent dosimeters (TLDs) were used to calculate the skin dose received by the 28 DUN patients. A total of 10 TLDs were used for each patient ( 5 for the Mepilex and 5 for the control patch); the TLDs were laid out on a grid, one in the centre and four in each of the corners, at a diagonal distance of $2 \mathrm{~cm}$ from the corner of the grid. The size of the grid was adjusted to the size of the patient. Measures for the 5 TLDs were averaged for each patch for each patient.

Diodes were used to electronically measure the dose delivered to the $10 \mathrm{ARO}$ patients. Diodes were placed centrally at the level of tattoos in the control and Mepilex Lite patches underneath any bolus. An average of the dose over three fractions was recorded.

The dose to the skin of the 23 patients from WGN and the 13 patients from PLN was estimated using the point dose function on the treatment planning systems Eclipse (Version 8.9 and 10.0 Varian Medical Systems Inc, Palo Alto, CA) and Xio (Release 4.62.00, CMS Software Elekta Group). The point dose was assessed at five locations in each of the study patches and the average skin dose was calculated for each patch. A tracing of the study area and translational measurements from the AP tattoo to each point of interest were taken. These measurements were used to locate each point of interest on the treatment planning system where the dose assessments were made.

\section{Exit questionnaire}

At the completion of the trial, patients were given an exit questionnaire which allowed them the opportunity to comment on different aspects of participating in the trial. 70 patients returned the questionnaire. Responses were entered into Microsoft Excel (2010) and subjected to a content analysis by DP and MJ (who was not involved in the trial). Inductively derived codes were grouped according to the emerging domains and peer checked to provide a comprehensive account of the participants' experiences.

\section{Statistical analysis}

SPSS 15.0 (IBM, Chicago, IL) was used for all the statistical analyses unless otherwise noted. The statistical significance between differences in Mepilex Lite and control RISRAS scores was determined by two-tailed paired t-test for combined and researcher scores (as these followed a normal distribution pattern, Figure 2), and by nonparametric Wilcoxon signed rank test for patient RISRAS scores (as these were not normally distributed, Figure 2). A binomial test (as a variant of the McNemar test for comparing paired binary variables) was used to determine the statistical significance of the difference between the incidence of moist desquamation in Mepilex Lite and control patches. In all cases, $\mathrm{p}<0.05$ was considered statistically significant. RISRAS scores and dose averages are given as averages \pm standard error of the mean (SEM). Chi-squared tests for independence (with Yates Continuity Correction) were used to determine the association between moist desquamation on one hand and the presence of bolus, Fitzpatrick skin type and smoking status on the other hand. Analysis of time to moist desquamation and time to healing was conducted using a mixed models analysis on those patients who experienced moist desquamation using SAS 9.1 (SAS Institute, Cary, NC) using PROC MIXED procedures (this method accounted for the pairing in the data for those patients who experienced MD in both control and Mepilex patch sites).

\section{Results}

A total of 80 patients were recruited for this trial with 74 patients yielding a complete data set for analysis (see consort diagram in Figure 
Citation: Paterson DB, Poonam P, Bennett NC, Peszynski RI, Van Beekhuizen MJ, et al. (2012) Randomized Intra-patient Controlled Trial of Mepilex Lite Dressings versus Aqueous Cream in Managing Radiation-Induced Skin Reactions Post-mastectomy. J Cancer Sci Ther 4: 347-356. doi:10.4172/1948-5956.1000166

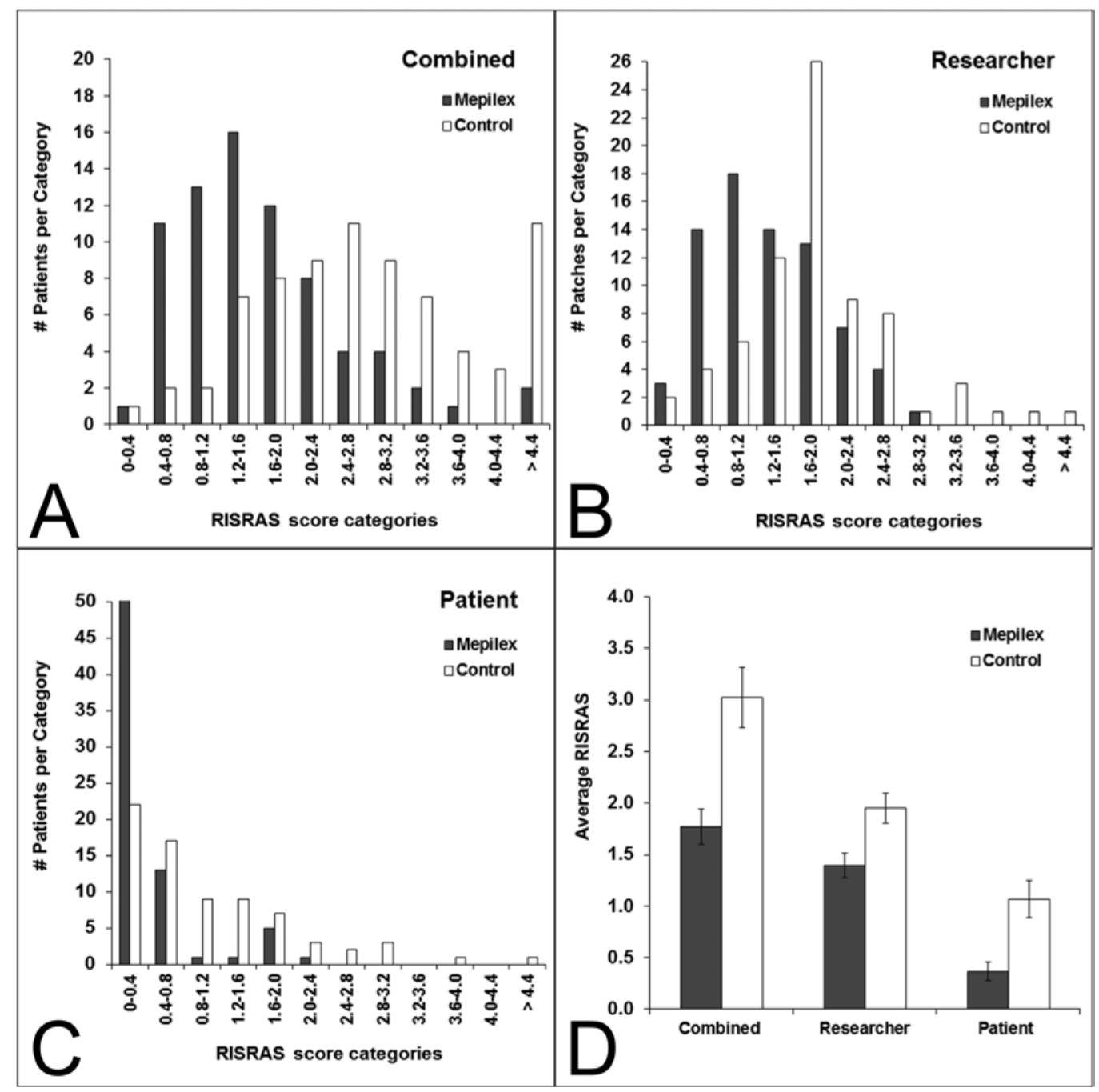

Figure 2: Distribution of Radiation-Induced Skin Reaction Assessment Scale (RISRAS) scores in categories. (A-C) and averaged over all trial patients (D). A-C: RISRAS scores of skin areas were grouped into categories and displayed as total number of skin areas per category, showing an overall normal distribution for the combined and researcher scores but not for the patient scores. D. RISRAS scores broken down in separate components and presented as mean values \pm SEM of 74 skin patches. Statistical significance of difference between dressings and cream was $<0.001$ using a two-tailed paired t-test for combined and researcher scores and Wilcoxon signed rank test for patient scores.

1). A breakdown of patient demographics for the four contributing Hospitals is given in Table 2 .

\section{Patient demographics}

A total of 80 women were recruited between March 2011 and May 2012. DUN recruited the most patients (29), followed by WGN (25), PLN (15) and ARO (11). The average age (54 years) and average weight $(74 \mathrm{~kg})$ did not differ much between centres. With respect to ethnicity, 66 women identified as European, 5 as Maori, 2 as Asian, 1 as Pacifica and 1 as Fijian-Indian. The vast majority (93\%) of women presented with stage II or III disease at the time of diagnosis. Only 1 patient had a boost which was outside the study area. Patient numbers were evenly split between centres with respect to whether the patients had chemotherapy before radiation (84\%), axillary node dissection (91\%), had never smoked (68\%), were ex-smokers $(26 \%)$ or were current smokers (7\%). With respect to skin type, $34 \%$ of patients had Fitzpatrick skin type I or II [17] (lowest in ARO with 0\%), 60\% of patients had skin type III or IV (highest in ARO with 90\%) and only 5\% had skin type V. None of the patients had skin type VI

\section{Mepilex lite and control patches received a similar dose}

Because the dose received by the skin is likely to affect the severity of the radiation-induced skin reactions, we calculated the skin doses received by half (38/74) of the patients either by TLDs (DUN) or diodes (ARO) and estimated the skin doses received by the remainder of the patients (WGN and PLM), using RT planning software. Table 3 shows that the average skin doses between Mepilex Lite and control patches were very similar in all four centres. Therefore any differences in skin reactions are unlikely to have been due to differences in dose between Mepilex Lite and control patches.

Mepilex lite dressings decrease the extent of radiationinduced skin reactions

Average combined and researcher RISRAS scores but not the patient RISRAS scores followed a normal distribution pattern (Figure 
Citation: Paterson DB, Poonam P, Bennett NC, Peszynski RI, Van Beekhuizen MJ, et al. (2012) Randomized Intra-patient Controlled Trial of Mepilex Lite Dressings versus Aqueous Cream in Managing Radiation-Induced Skin Reactions Post-mastectomy. J Cancer Sci Ther 4: 347-356. doi:10.4172/1948-5956.1000166

\begin{tabular}{|c|c|c|c|c|c|}
\hline & DUN (\%) & WGN (\%) & PLM (\%) & ARO (\%) & Combined (\%) \\
\hline Total enrolled & 29 & 25 & 15 & 11 & $80(100)$ \\
\hline Total completed & $28(37.8)$ & $23(31.1)$ & $13(17.6)$ & 10 (13.5) & $74(100)$ \\
\hline Average age $(y)$ & $55.2(32-84)$ & $52.1(33-73)$ & $53.1(29-74)$ & $55.3(40-74)$ & $53.9(32-84)$ \\
\hline Average weight (kg) & $71.4 \pm 16.7$ & $72.4 \pm 16.1$ & $77.5 \pm 17.4$ & $76.6 \pm 14.8$ & $73.5 \pm 16.3$ \\
\hline \multicolumn{6}{|l|}{ Ethnicity\# } \\
\hline NZ European & $25(89.3)$ & $18(78.3)$ & $11(84.6)$ & $8(80.0)$ & $62(83.8)$ \\
\hline NZ Maori & $1(3.6)$ & $3(13.0)$ & $1(7.7)$ & $0(0)$ & $5(6.8)$ \\
\hline Pacific Islander & $1(3.6)$ & $0(0)$ & $0(0)$ & $0(0)$ & $1(1.4)$ \\
\hline European other & $1(3.6)$ & $1(4.3)$ & $0(0)$ & $2(20.0)$ & $4(5.4)$ \\
\hline Fiji-Indian & $0(0)$ & $1(4.3)$ & $0(0)$ & $0(0)$ & $1(1.4)$ \\
\hline Asian & $0(0)$ & $1(4.3)$ & $1(7.7)$ & $0(0)$ & $2(2.7)$ \\
\hline \multicolumn{6}{|l|}{ Disease Stage } \\
\hline 1 & $3(10.7)$ & $1(4.3)$ & $1(7.7)$ & $0(0)$ & $5(6.8)$ \\
\hline II & $14(50.0)$ & $4(17.4)$ & $6(46.2)$ & $5(50.0)$ & $29(39.2)$ \\
\hline III & $11(39.3)$ & $17(73.9)$ & $6(46.2)$ & $5(50.0)$ & $39(52.7)$ \\
\hline N/A & $0(0)$ & $1^{* *}(4.3)$ & $0(0)$ & $0(0)$ & $1(1.4)$ \\
\hline \multicolumn{6}{|l|}{ Treatment Modality } \\
\hline Photons & $28(100)$ & $23(100)$ & $13(100)$ & $3(30.0)$ & $67(90.5)$ \\
\hline Electrons & $0(0)$ & $0(0)$ & $0(0)$ & $7(70.0)$ & $7(9.5)$ \\
\hline \multicolumn{6}{|l|}{ Prescribed Dose } \\
\hline 50Gy/25\# & $26(92.8)$ & $22(95.7)$ & $10(76.9)$ & $10(100.0)$ & $68(91.9)$ \\
\hline 46Gy/20\# & $1(3.6)$ & $0(0)$ & $0(0)$ & $0(0)$ & $1(1.4)$ \\
\hline 45Gy/25\# & $0(0)$ & $1(4.3)$ & $0(0)$ & $0(0)$ & $1(1.4)$ \\
\hline $52 G y / 26 \#$ & $1(3.6)$ & $0(0)$ & $0(0)$ & $0(0)$ & $1(1.4)$ \\
\hline 40Gy/15\# & $0(0)$ & $0(0)$ & $3(23.1)$ & $0(0)$ & $3(4.0)$ \\
\hline \multicolumn{6}{|l|}{ Bolus } \\
\hline None & $22(78.6)$ & $0(0)$ & $1(7.7)$ & $1(10)$ & $24(32.4)$ \\
\hline $3 \mathrm{~mm}$ & $0(0)$ & $23(100)$ & $9(69.2)$ & $1(10.0)$ & $33(44.6)$ \\
\hline $4 \mathrm{~mm}$ & $0(0)$ & $0(0)$ & $0(0)$ & $1(10.0)$ & $1(1.4)$ \\
\hline $5 \mathrm{~mm}$ & $6(21.4)$ & $0(0)$ & $3(23.1)$ & $7(70.0)$ & $16(21.6)$ \\
\hline \multicolumn{6}{|l|}{ Boost } \\
\hline Yes & $0(0)$ & $1(4.3)$ & $0(0)$ & $0(0)$ & $1(1.4)$ \\
\hline No & $28(100)$ & $22(95.7)$ & $13(100)$ & $10(100.0)$ & $73(98.6)$ \\
\hline \multicolumn{6}{|l|}{ Axillary Node Dissection } \\
\hline Yes & $24(85.7)$ & $21(91.3)$ & $13(100)$ & $9(90.0)$ & 67 (90.5) \\
\hline No & $4(14.2)$ & $2(8.7)$ & $0(0)$ & $1(10.0)$ & $7(9.5)$ \\
\hline \multicolumn{6}{|l|}{ Chemotherapy } \\
\hline None & $6(21.4)$ & $3(13.0)$ & $2(15.4)$ & $2(20.0)$ & $13(17.6)$ \\
\hline Before RT & $22(78.6)$ & $19(82.6)$ & $3(23.1$ & $8(80.0)$ & $52(70.3)$ \\
\hline Concurrent & $0(0)$ & $1(4.3)$ & $8(621.5$ & $0(0)$ & $9(12.2)$ \\
\hline \multicolumn{6}{|l|}{ Fitzpatrick Skin type [17] } \\
\hline I & $4(14.2)$ & $2(8.7)$ & $2(15.4)$ & $0(0)$ & $8(10.8)$ \\
\hline II & $7(25.0)$ & $6(26.1)$ & $4(30.8)$ & $0(0)$ & $17(23.0)$ \\
\hline III & $11(39.3)$ & $10(43.5)$ & $5(38.5)$ & $9(90.0)$ & $34(45.9)$ \\
\hline IV & $5(17.9)$ & $3(13.0)$ & $1(7.7)$ & $1(10.0)$ & $10(13.5)$ \\
\hline v & $1(3.6)$ & $2(8.7)$ & $1(7.7)$ & $0(0)$ & $4(5.4)$ \\
\hline VI & $0(0)$ & $0(0)$ & $0(0)$ & $0(0)$ & $0(0)$ \\
\hline \multicolumn{6}{|l|}{ Smoker } \\
\hline Current & $2(7.1)$ & $1(4.3)$ & $1(7.7)$ & $1(10.0)$ & $5(6.8)$ \\
\hline Ex & $7(25.0)$ & $7(30.4)$ & $3(23.1)$ & $2(20.0)$ & $19(25.7)$ \\
\hline No & $19(67.9)$ & $15(65.2)$ & $9(69.2)$ & $7(70.0)$ & $50(67.6)$ \\
\hline
\end{tabular}

NS: not specified; NA: not applicable; * some people identify with more than one ethnicity; ${ }^{* *}$ patient had a phyllodes tumour.

Table 2: Patient demographics. 
Citation: Paterson DB, Poonam P, Bennett NC, Peszynski RI, Van Beekhuizen MJ, et al. (2012) Randomized Intra-patient Controlled Trial of Mepilex Lite Dressings versus Aqueous Cream in Managing Radiation-Induced Skin Reactions Post-mastectomy. J Cancer Sci Ther 4: 347-356. doi:10.4172/1948-5956.1000166

2A-C). More Mepilex Lite than control patches fell into the lower RISRAS categories, as evidenced by the distinctive shift of black bars to the left in figures $2 \mathrm{~A}-\mathrm{C}$. When the average RISRAS scores were calculated (Figure 2D), the decrease in skin reaction severity was statistically highly significant for both the combined and researcher RISRAS (t-test: $\mathrm{p}<0.001$ ) as well as for the patient RISRAS component (Wilcoxon signed rank test: $\mathrm{p}<0.001$ ) in favour of Mepilex Lite. The reduction in overall severity of the skin reactions as shown by the combined RISRAS scores was $41 \%(\mathrm{p}<0.001)$. Photographs taken of the skin of trial patients clearly demonstrates the effect of Mepilex Lite dressings on their skin reactions (Figure 3 ).

\section{Mepilex lite dressings do not significantly decrease the incidence of moist desquamation}

Fewer skin patches covered in Mepilex Lite dressings developed moist desquamation (MD) compared with skin patches treated with aqueous cream (15\% and 19\% respectively), however this difference was not statistically significant (binomial test: $p>0.05$ ). The incidence of MD in the study areas was much lower than expected and differed between the four centres (Table 4).

Mepilex Lite did not affect the average time to developing MD nor the average time to healing. However when the MD component of the RISRAS was averaged for all patients who developed MD in the study area, this was significantly lower for the Mepilex Lite patches ( 0.37 and 0.18 respectively: $p=0.043$ ). If the number of days of moist desquamation of each Mepilex Lite patch was added up and compared with that of the control patches, the total number of MD weeks of the Mepilex Lite patches was found to be $28 \%$ lower compared with that of the control patches (Table 5).

\section{Factors that may influence the severity of radiation-induced skin reactions}

Chi-square tests for independence (with Yates Continuity Correction) for the entire cohort demonstrated that the use of bolus was significantly associated with moist desquamation anywhere on the chest wall $(\mathrm{p}<0.001)$. Moist desquamation occurred in $64 \%$ of

\begin{tabular}{|l|c|c|c|}
\hline Dose (Gy) & DUN & WGN & PLM \\
\hline MepilexLite & $40.1 \pm 1.4$ & $47.0 \pm 0.6$ & $43.4 \pm 1.4$ \\
\hline Control & $40.4 \pm 1.6$ & $46.2 \pm 0.7$ & $43.4 \pm 1.6$ \\
\hline p values* & 0.91 & 0.34 & 0.95 \\
\hline
\end{tabular}

*paired 2-tailed student t-test.

Table 3: Average skin dose ( \pm SEM) in the four centres.

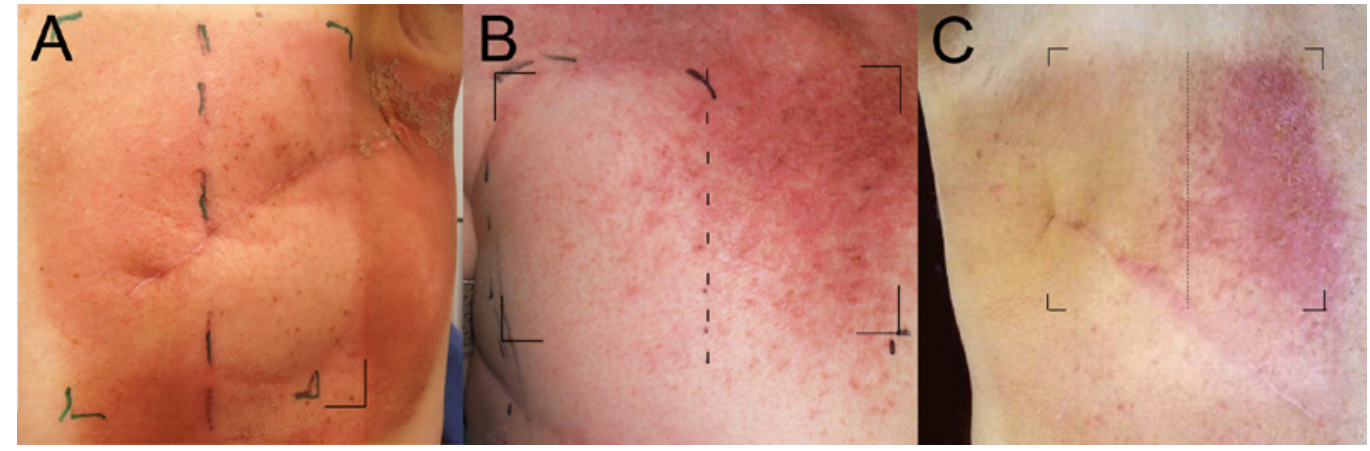

Figure 3: Photographs of skin showing the effect of Mepilex Lite dressings on skin reactions. Patient A: at 1 week follow up; Patient B: after 30 Gy; Patient C: at 1 week follow up. Areas in brackets are the study area.In each case the brightly red skin had been treated with aqueous cream and the lighter coloured skin had been covered with Mepilex Lite dressings.

\begin{tabular}{|c|c|c|c|c|c|}
\hline & \# Patients analysed & \# Patients with MD in control & \# Patients with MD in mepilex & Total \# patients with MD & $\%$ Patients with MD \\
\hline DUN & 28 & 0 & 0 & 4 & 14 \\
\hline WGN & 23 & 4 & 4 & 15 & 65 \\
\hline ARO & 10 & $2^{*}$ & 2 & 3 & 30 \\
\hline PLM & 13 & $8^{* *}$ & 5 & 13 & 100 \\
\hline Total & 74 & 14 & 11 & 35 & 47 \\
\hline$\%$ total & 100 & 19 & 15 & 47 & \\
\hline
\end{tabular}

*Both patients developed MD in control and Mepilex patches. **Five of the eight patients developed MD in control and Mepilex patches.

Table 4: Incidence of moist desquamation between the four centres. 


\begin{tabular}{|l|l|l|l|}
\hline Moist desquamation & Control & Mepilex & p values \\
\hline Incidence & $19 \%$ & $15 \%$ & 0.55 \\
\hline Time to MD & $40 \pm 3$ days & $40 \pm 3$ days & 0.93 \\
\hline Time to healing & $13 \pm 2$ days & $11 \pm 2$ days & 0.49 \\
\hline MD RISRAS score & 0.37 & 0.18 & 0.043 \\
\hline Total MD time & 25 weeks & 18 weeks & NA $^{*}$ \\
\hline
\end{tabular}

*Not applicable: these are a summation of all the individual patches in each arm

Table 5: Moist desquamation parameters.

patients receiving bolus and $12.5 \%$ of patients who did not receive bolus. Because some skin types (based on the Fitzgerald Skin Types) were poorly represented in our cohort, patient data had to be pooled for statistical analysis. When comparing skin types I-III with skin types IV-VI, moist desquamation was not associated with skin type. There was also no association between moist desquamation and smoking when data from current smokers were compared with those of exsmokers and patients who had never smoked before.

\section{Patients' perspective}

All participants scored their skin reactions based on subjective sensations as part of the RISRAS. Mepilex Lite dressings scored significantly better than aqueous cream with respect to pain/ discomfort, itchiness, burning and the effect on day to day life (Figure 2D). In addition, 70 out of 74 participants (95\%) returned the exit questionnaire they were given after they completed the trial in which they were asked to comment on their trial experience. When asked whether taking part in the trial had been a positive experience, $99 \%(n=69)$ of participants responded positively. A quarter of the participants $(n=17)$ commented that the close surveillance of skin reactions during radiation treatment gave them peace of mind and this equated to superior care. The additional follow-up appointments after treatment completion were found reassuring and were seen as a "safety net" by several women (13\%). Many women (37\%) expressed an altruistic view; they wanted to make the cancer journey easier for future breast cancer patients. In fact all participants said that they would take part in similar clinical trials in the future.

Next, participants were asked about their experience with using Mepilex Lite dressings. When asked specifically, $80 \%$ of participants said they preferred the dressings over the cream. Most women commented that the dressings were easy to apply (71\%) and comfortable or comforting to wear (56\%) and provided protection (26\%) from friction. Participants described how the Mepilex Lite dressings decreased feelings of itchiness (30\%), pain (11\%) burning (9\%) and irritation (10\%). Some participants thought that skin patches underneath the dressings were less red (21\%), did not peel so easily (13\%) and healed faster (14\%) compared with the control patches.

Only six women preferred aqueous cream over Mepilex Lite dressings. Although the Safetac technology ensures that the dressings adhere to healthy skin, half of the women reported that they did not stick well in the axilla, during the night or when the patient perspired. In addition, three patients reported that removing the dressings hurt a little and two participants found the dressings itchy.

\section{Discussion}

In this study we show for the first time that Mepilex Lite dressings decreased the severity of the full range of acute radiation-induced skin reactions in breast cancer patients post-mastectomy by $41 \%$ (using combined RISRAS scores). These differences in skin reaction severity were unlikely to have been due to differences in dose received between treatment and control patches.

Compared with the control patches, dressings did not significantly reduce the incidence of moist desquamation. The average MD RISRAS score was $49 \%$ lower for Mepilex Lite patches compared with control patches. In addition, the cumulative MD time in the Mepilex Lite patches was reduced by $28 \%$ from 25 to 18 weeks. This is a clinically significant finding because a decrease in total MD time reduces the chances of developing infection and scarring (a long-term consequence of acute skin inflammation).

Surprisingly, the incidence of MD in our cohort was much lower than that previously reported in the literature [16]. However, this is not a true reflection of the real MD incidence in our cohort but rather a consequence of the way the study areas were allocated. In order to facilitate statistical analysis we only allocated one study area per patient for analysis. For consistency purposes we choose to incorporate only the very first skin area that became erythematous for analysis. We subsequently found that, as radiation treatment progressed, many patients developed erythema over the entire chest wall and that the first erythemateous area was not always the area that progressed to moist desquamation. We carefully noted the incidence and location of MD in all areas of the chest wall (Table 3) and observed that a total of $47 \%$ of patients developed MD somewhere on the chest wall, which is more similar to the rates reported by Graham, et al. [16].

Another unexpected finding was the degree of variation in moist desquamation rates between the four centres, with DUN reporting the lowest MD rates. However, most of the DUN patients did not receive bolus, which reduced their average skin dose substantially and resulted in only one of the 22 no bolus patients developing moist desquamation compared with three of the six bolus patients. The presence of bolus was significantly associated with moist desquamation over the entire cohort. In support of this, a large study of 351 patients, 226 of whom were breast cancer patients, also reported a significant association between bolus and acute skin reaction severity [6].

The effect of smoking on the severity of acute skin reactions is not universally supported. We did not find a correlation between smoking and moist desquamation in our small cohort of 74 post mastectomy patients. Larger studies, such as those conducted by Turesson, et al. [20] with 402 breast cancer patients and Twardella, et al. [21] with 478 breast cancer patients both reported a lack of correlation between smoking and severity of acute skin reactions. In contrast to these studies, Wells et al. [6] did find that smokers were significantly more likely to have severe acute skin reactions in their cohort of 351 patients.

Anecdotal evidence suggests that individuals with pale or fair skin experience more severe radiation-induced skin reactions than those with darker skin; similar to the tendency of lighter skin to get sun burnt more easily than darker skin. A lack of empirical data exists to support this claim [22]. In fact, Ryan, et al. [23] found that AfricanAmerican women reported more severe skin reactions than Caucasian women post-radiation therapy to the breast. Perhaps early reactions are more difficult to see on darker skin and are therefore not managed appropriately at an early stage, resulting in more severe reactions at a later stage. We did not find a significant association between skin reactions and different Fitzpatrick skin types. In order to determine the 
Citation: Paterson DB, Poonam P, Bennett NC, Peszynski RI, Van Beekhuizen MJ, et al. (2012) Randomized Intra-patient Controlled Trial of Mepilex Lite Dressings versus Aqueous Cream in Managing Radiation-Induced Skin Reactions Post-mastectomy. J Cancer Sci Ther 4: 347-356. doi:10.4172/1948-5956.1000166

statistical significance of skin type on moist desquamation, we had to pool data from skin types I-III and IV-VI, which is not ideal. However, the larger study by Wells, et al. [6] also reported a lack of association between skin type and severity of radiation-induced skin reactions.

One observation that has also been made by other authors was that the severity of the skin reactions peaked for many patients 1 or 2 weeks after completion of treatment $[3,16,24]$. Patients are therefore most likely to need additional support and expert advice during this time to ensure optimal management of skin reactions, particularly of moist desquamation. A discussion paper by Cumming and Routsis [24] explored the improvements needed in the follow-up of acute skin reactions from breast RT and suggest telephone follow-up by an RT or an RT-led follow-up clinic 1-2 weeks post-treatment.

Most of the participants found taking part in this trial a positive experience. Like many other studies [23-25] our participants were motivated by altruistic thoughts when choosing to enrol in a clinical trial. The preconception that trial participants receive superior care has also been reported before [26]. From a patient's perspective, the Mepilex Lite dressings were far superior to the aqueous cream. This was evident from the patient component of the RISRAS as well as from specific comments in the exit questionnaire. Other studies have also reported that Mepilex Lite dressings are easy to apply, comfortable to wear, reduce friction, pain and itching and improve day to day functioning $[13,14]$. Interestingly, a small number of participants in our trial and two participants in the study conducted by MacBride, et al. [14] mentioned that Mepilex Lite dressings were itchy. Similarly, a few patients found the dressings painful to remove. In the radiation therapy setting, the dressings have only a small bolus effect [13] and radiation therapy could be given through the dressings. However, they are not transparent and need to be taken off during radiation treatment whenever they cover up tattoos. In addition, the dressings do not stick sufficiently well in "awkward" areas, such as the axilla (this trial) and infra-mammary fold [13], on patients that perspire a lot.

\section{Limitations}

Our previous pilot study [13] was limited by its small size (24 patients), the lack of computer-generated randomization schedules, absence of actual dose measurements on the Mepilex and control patches, a trial endpoint of dry desquamation and a lack of blinding. The current study is much larger (74 patients), properly randomized and takes into account the entire scale of acute skin reactions. We powered our study based on a very similar study by Graham and colleagues, who investigated the effect of No-Sting Barrier Film against sorbolene cream on the severity of skin reaction in 61 post-mastectomy patients in Australia [16]. We measured the dose received by the Mepilex Lite and control patches in half of our patients (38/74) and estimated the skin dose of the remaining patients using RT planning systems. We found that the dose delivered to Mepilex Lite and control patches was very similar and was therefore not a confounding factor in this trial. Unfortunately due to the nature of using a dressing and a cream, we could not blind the trial. This is a limitation of any trial that uses interventions that are easily distinguished by patients and researchers. Although we did take some photographs to illustrate the effect of the dressings, we did not have the resources to photograph every patient every time we assessed their skin. However, using an intra-patient randomization method, recruiting only post-mastectomy patients who present a very homogenous skin area for comparison, and giving similar doses to Mepilex Lite and control patches, make this a robust trial.

The biggest limitation of the current study is the fact that we only used the very first area that presented with a skin reaction for analysis. A total of 17 (23\%) patients developed moist desquamation outside the study area, and in each instance this was in the axilla. The axilla is a prime area for moist desquamation because of additional mechanical (friction with clothing and arm) and moisture damage characteristic of this area. We found that the Mepilex Lite dressings didn't stick well in the axilla. In future trials, we intend to explore the use of Mepitel Film dressings on the management and prevention of radiation-induced skin reactions. These dressings stick better to healthy skin and are transparent so they can be kept on during treatment and they can also stay on in the shower [27].

\section{Conclusion}

This trial has demonstrated that, compared with aqueous cream, Mepilex Lite dressings decrease the severity of all skin reactions, including moist desquamation. The dressings did not affect the time to developing or the time to healing moist desquamation. Finally, the vast majority of the patients find them easy to use and very comfortable to wear.

\section{Acknowledgements}

The authors wish to thank Dr James Stanley for the generation of randomization sheets and advice regarding statistical analysis, and the following people for their contribution to data collection: Annie Sutherland and Jo Tuaine (Dunedin Hospital), Jenni Reeves and Ruth Wickens (Wellington Hospital), Hannah Thompson (Palmerston North Hospital), Anita Williams, Jennifer Bretherton, Pamela Stanners (Auckland Radiation Oncology) and Jayne Bowers (clinical trials unit, Wellington Hospital) for data storage.

This research was funded by Molnlycke Healthcare LTD who supplied the dressings free of charge; the University of Otago, the New Zealand Breast Cancer Foundation, Capital and Coast District Health Board, the Wellington Division of the Cancer Society and the Rouse Education Trust.

\section{Conflict of Interest Statement}

The authors declare no conflict of interest.

\section{References}

1. Wells M (2003) Radiation skin reactions. Faithfull S (Ed) Supportive care in radiotherapy. London: Churchill Livingstone 135-159.

2. Kumar S, Juresic E, Barton M, Shafiq J (2010) Management of skin toxicity during radiation therapy: a review of the evidence. J Med Imaging Radiat Oncol 54: 264-279.

3. D'haese S, Bate T, Claes S, Boone A, Vanvoorden V, et al. (2005) Management of skin reactions during radiotherapy: a study of nursing practice. Eur $\mathrm{J}$ Cancer Care 14: 28-42.

4. D'haese S, Van Roy M, Bate T, Bijdekerke P, Vinh-Hung V (2010) Management of skin reactions during radiotherapy in Flanders (Belgium): a study of nursing practice before and after the introduction of a skin care protocol. Eur $\mathrm{J}$ Oncol Nurs 14: $367-372$

5. Bolderston A (2003) Skin care recommendations during radiotherapy: a survey of Canadian practice. Can J Med Radiat Technol 34: 3-11.

6. Wells M, Macmillan M, Raab G, MacBride S, Bell N, et al. (2004) Does aqueous or sucralfate cream affect the severity of erythematous radiation skin reactions? A randomised controlled trial. Radiother Oncol 73: 153-162.

7. Bolderston A, Lloyd NS, Wong RK, Holden L, Robb-Blenderman L (2006) The prevention and management of acute skin reactions related to radiation therapy: a systematic review and practice guideline. Support Care Cancer 14 802-817.

8. Vavassis P, Gelinas M, Chabot Tr J, Nguyen-Tân PF (2008) Phase 2 study of silver leaf dressing for treatment of radiation-induced dermatitis in patients receiving radiotherapy to the head and neck. J Otolaryngol Head Neck Surg 
Citation: Paterson DB, Poonam P, Bennett NC, Peszynski RI, Van Beekhuizen MJ, et al. (2012) Randomized Intra-patient Controlled Trial of Mepilex Lite Dressings versus Aqueous Cream in Managing Radiation-Induced Skin Reactions Post-mastectomy. J Cancer Sci Ther 4: 347-356. doi:10.4172/1948-5956.1000166

37: 124-129.

9. Mak SS, Zee CY, Molassiotis A, Chan SJ, Leung SF, et al. (2005) A comparison of wound treatments in nasopharyngeal cancer patients receiving radiation therapy. Cancer Nurs 28: 436-445.

10. Kirova YM, Fromantin I, De Rycke Y, Fourquet A, Morvan E (2011) Can we decrease the skin reaction in breast cancer patients using hyaluronic acid during radiation therapy? Results of phase III randomised trial. Radiother Oncol 100: 205-209.

11. Macmillan MS, Wells M, MacBride S, Raab GM, Munro A (2007) Randomized comparison of dry dressings versus hydrogel in management of radiationinduced moist desquamation. Int J Radiat Oncol Biol Phys 68: 864-872.

12. Gollins S, Gaffney C, Slade S, Swindell R (2008) RCT on gentian violet versus a hydrogel dressing for radiotherapy-induced moist skin desquamation. J Wound Care 17: 268-270, 272, 274-275.

13. Diggelmann KV, Zytkovicz AE, Tuaine JM, Bennett NC, Kelly LE, et al. (2010) Mepilex Lite dressings for the management of radiation-induced erythema: a systematic inpatient controlled clinical trial. Br J Radiol 83: 971-978.

14. MacBride SK, Wells ME, Hornsby C, Sharp L, Finnila K, et al. (2008) A case study to evaluate a new soft silicone dressing, Mepilex Lite, for patients with radiation skin reactions. Cancer Nurs 31: E8-E14.

15. Adamietz I, Mose S, Harberl A (1995) Effect of self-adhesive, silicone-coated polyamide net dressing on irradiated human skin. Oncol Investig 2: 277-285.

16. Graham P, Browne L, Capp A, Fox C, Graham J, et al. (2004) Randomized, paired comparison of No-Sting Barrier Film versus sorbolene cream $(10 \%$ glycerine) skin care during postmastectomy irradiation. Int J Radiat Oncol Biol Phys 58: 241-246.

17. Fitzp atrick TB (1975) The validity and practicality of sun reactive skin types I through VI. Arch Dermatol 124:869-871.
18. Noble-Adams R (1999) Radiation-induced skin reactions. 2: Development of measurement tool. Br J Nurs 8: 1208-1211.

19. Noble-Adams R (1999) Radiation-induced skin reactions. 3: Evaluating the RISRAS. Br J Nurs 8:1305-1312.

20. Turesson I, Nyman J, Holmberg E, Odén A (1996) Prognostic factors for acute and late skin reactions in radiotherapy patients. Int $\mathrm{J}$ Radiat Oncol Biol Phys 36: 1065-1075.

21. Twardella D, Popanda O, Helmbold I, Ebbeler R, Benner A, et al. (2003) Personal characteristics, therapy modalities and individual DNA repair capacity as predictive factors of acute skin toxicity in an unselected cohort of breas cancer patients receiving radiotherapy. Radiother Oncol 69: 145-153.

22. Porock D (2002) Factors influencing the severity of radiation skin and ora mucosal reactions: development of a conceptual framework. Eur $\mathrm{J}$ Cancer Care (Engl) 11: 33-43.

23. Ryan JL, Bole C, Hickok JT, Figueroa-Moseley C, Colman L, et al. (2007) Post-treatment skin reactions reported by cancer patients differ by race, not by treatment or expectations. Br J Cancer 97: 14-21.

24. Cumming J, Routsis D (2009) Are improvements needed in the management of severe acute skin reactions following completion of breast radiotherapy? A discussion of some possible service options. J Radiother Pract 8: 11-16.

25. Jenkins V, Fallowfield $L$ (2000) Reasons for accepting or declining to participate in randomized clinical trials for cancer therapy. $\mathrm{Br} \mathrm{J}$ Cancer 82: 1783-1788.

26. Julian-Reynier C, Genève J, Dalenc F, Genre D, Monnier A, et al. (2007) Assessment of care by breast cancer patients participating or not participating in a randomized controlled trial: a report with the Patients' Committee for Clinical Trials of the Ligue Nationale Contre le Cancer. J Clin Oncol 25: 3038-3044.

27. Ellis PM, Butow PN, Tattersall MH, Dunn SM, Houssami N (2001) Randomized clinical trials in oncology: understanding and attitudes predict willingness to participate. J Clin Oncol 19: 3554-3561. 